\title{
Code-switching Between English and Russian with Russian Heritage Speakers, Born and Raised in Russian-speaking Families in the USA
}

DELIYA KULESHOVA

Purdue University

\section{ABSTRACT}

Code-switching is one of the major areas in the field of Bilingualism. Code-switching describes the processes of switching between languages among those who know and speak more than one language. This article will analyze the code-switching between Russian and English in Russian heritage speakers. They are first year students at a large Midwestern university, born in the U.S. to Russian-speaking parents. They have been taking university Russian classes for two semesters. The students were asked to record two five-minute dialogues with their parents who also speak Russian and English. There was neither instruction to use solely Russian, nor the use of English was prohibited. The goal of the research was to count and analyze the instances of code-switching between Russian and English, and prove or reject the hypothesis that there would be fewer codeswitching instances in the dialogue devoted to a family holiday versus the dialogue devoted to university classes. The dialogue topics were furnished beforehand, however, no preparation was asked. The speech was asked to be spontaneous and natural. The findings proved the hypothesis that code-switching instances in the first dialogue were less frequent, so the students were mainly using only one language - Russian - without switching to English very often. The second dialogue revealed more code-switching instances as was initially supposed. Conclusions and directions for future research are presented. 
Keywords: translanguaging, code-switching, bilingualism, heritage speakers, Russian heritage speakers.

\section{Introduction}

Before coming to the U.S. I never heard the term "heritage speakers", neither in Russian, nor in English. Only after I started teaching Russian in the U.S., I came across students who were born either in Russia or in the U.S., but were raised mostly in the U.S., had one or two Russianspeaking parents, and had some knowledge of Russian. I learned that such students are called heritage speakers, know both English and Russian, but to a different extent, and practice codeswitching in their daily life. As Carreira \& Kagan (2011) state, "typically, the foreign-born individuals retain strong skills in the HL [heritage language], while second- and especially thirdgeneration speakers show evidence of incomplete acquisition and loss of linguistic structures" (p. 41). The heritage speakers who are research participants in this article are second generation speakers (born in the U.S.), therefore, they rarely show complete mastery of their heritage language. This fact always intrigued me as a Russian native speaker, an EFL learner, a firstgeneration immigrant, a researcher, and a teacher. I agree with Maria Polinsky who says, "the reason those heritage languages are interesting is that they allow us to see what is vulnerable and what's strong in human language in general" (Polinsky, 2014). While teaching Russian here in the U.S., I was constantly observing heritage speakers' language behavior and differences in their Russian language acquisition in comparison with foreign language learners. Finally, I managed to conduct a pilot study and analyze heritage speakers' code-switching behavior.

\section{Literature Review}

What is code-switching? "It is an alternate use of two or more languages in the same utterance or conversation" (Stavans \& Porat, 2019, p. 123). Code-switching is the most typical 
linguistic phenomenon unique to bilinguals and multilinguals. As Roth (2005) points out, "codeswitching is the most visible form of bilingualism" (p.485). Nowadays code-switching is already a norm rather than an exception.

In literature, there are more publications on code-switching between Russian and Hebrew among Russian-Hebrew bilinguals than Russian-English bilinguals. It is easily explained: around eight hundred and fifty thousand Jewish repatriates moved to Israel from the former Soviet Union after 1989 (Remennick, 1999). By that date it is a larger number compared to the immigrants of Russian origin in the USA (Library of Congress, 2020). After the collapse of the USSR, lots of Russian-speaking people immigrated to the U.S. Therefore, today the generation of their kids and grandkids are those heritage speakers who present the research interest in this article. Such famous researchers as Maria Polinsky and Olga Kagan contributed a lot into the field of Russian heritage language, however, there is still a gap in the literature on RussianEnglish code-switching and the analysis of the code-switched instances.

From what is known, code-switching includes borrowing and transfer (Marian \& Kaushanskaya, 2006). More specifically, "borrowing is an overt verbal behavior consisting of the speaker "switching" into the other language and actively using single words or entire phrases from that language, while transfer is a covert behavior consisting of the speaker using the target language in a way that is semantically or syntactically appropriate for the other language (but not for the target language), without overtly switching languages” (Marian \& Kaushanskaya, 2006, p. 369). Naiditch (2000), who analyzed code-switching among Russian-Hebrew bilinguals (i.e. Russians who migrated to Israel or were born in Russian-speaking families in Israel), suggests that code-switching in daily life can be explained by a number of reasons: 1) the regularity of word usage; 2) the degree of integration of corresponding lexemes into the phonetic, 
grammatical and lexical system of Russian; 3) its stylistic markedness (as foreign, unusual, etc.) or neutrality. Another reason for code-switching, as suggested by Williams et al. (2019), is emotional arousal. According to their study, “emotional arousal, especially negative arousal, reduces cognitive control and may trigger spontaneous code-switching” (p. 830).

\section{Experiment Design}

The current study was conducted using convenience sampling. The participants were two heritage speakers from the Russian 101 class that I was teaching. Before giving out the assignment, I checked with what members of their family they spoke mainly Russian. The point of asking this question was to make sure that the heritage speakers were not going to use English only because I knew that, for example, they usually spoke English with their siblings. Student 1: Natasha (pseudonim), freshman, female, born and raised in Minnesota, parents born and raised in the USSR, mentioned that she usually spoke Russian with her mother, and mostly English with her father and her younger sister. Therefore, her task was to speak with her mother only. Student 2: Victor (pseudonim), freshman, male, born and raised in Florida, parents born and raised in the USSR, mentioned that he usually spoke Russian with his mother and father, but at the time of experiment his mother was away, and that Victor spoke mostly English with his younger brother, therefore his task was to speak to his father only. Specifically, Natasha's and Victor's task was to record two five-minute audio dialogues with their parents via voice recorder application. From my side, there was neither instruction to use only Russian, nor the use of English was prohibited. The participants were told that their natural spontaneous speech was needed.

The topics of the dialogues were chosen according to potential code-switching words that I expected to hear. The topic of the first dialogue was "Family holiday". My hypothesis was that the students would hardly code-switch because that topic was familiar to them, and they had 
surely discussed their family holidays with their families multiple times, therefore the majority of the words should have been familiar to them, and the students would use mostly Russian. The topic of the second dialogue was "My next semester: what classes I am going to take \& How COVID-19 might influence my studies". This topic was academically complex, so I anticipated to hear more examples of code-switching from Russian into English because the language of the students' coursework was English, and they hardly ever used the name of their classes in Russian before. Marian \& Kaushanskaya (2006) in their study of Russian-English bilinguals hypothesized that patterns of language borrowing and transfer "would be similarly influenced by the language in which the content was encoded and that bilinguals would show more crosslinguistic interaction when speaking about an event that took place in the other language" (p. 370).

As Heredia \& Altarriba (2001) state, "bilingual speakers often code-switch from one language to another, especially when both languages are used in the environment" (p. 164). According to Sichyova (2005), "the three affecting factors on Russian-English code-switching are: (1) the social contexts in which each language is learned; (2) the specific function for which each language is customarily employed; and (3) the efficacy of a language as a communicative tool in the society where it is used" (p. 487). Referring to this categorization of factors, my experiment was primarily implying the factor (2): the specific function for which each language is customarily employed. This way, the dialogue 1 "Family holiday" has a different function than dialogue (2) "My next semester". While dialogue 1 aimed at shared equal discussion of the family holiday (social function), dialogue 2 was student-centered and aimed at students sharing their academic plans for the next semester (academic function). 
Four dialogues and the analysis are presented below. I have analyzed each case of codeswitching according to the similar studies (Marian \& Kaushanskaya (2006); Roth (2005); Naiditch (2000)), my experience with hearing and analyzing the speech of Russian heritage speakers in the U.S., and my Russian-English code-switching practices myself. The dialogues were recorded in Russian, with English code-switching instances. Then, the dialogues were translated into English by the author of this article.

\section{Dialogues}

\section{Dialogue 1 "Family holiday"}

Student 1 - Natasha, 18, female.

Translated from Russian into English. Bold is used to highlight the instances of code-switching. 1 - Hi mom! How are you?

2 - Good, how are you, honey?

3 - Doing ok. I wanted to ask you about E's birthday.

4 - It's coming soon, at the end of the month. What did you want to ask?

5 - What are we going to do for her birthday?

6 - Well, she wanted dinner with family and some friends, but now because of the situation with coronavirus, I am afraid she won't be able to invite her friends. So, probably there are going to be only us. I hope you can come!

7 -Yes, I can come and help fixing dinner for everybody!

8 - Sounds great! When are you coming?

9 - I think I should come this Friday.

10 - That would be wonderful! She asked me if we could have that cake.. Do you remember we always buy the one at Dobbie's... It's a raspberry-chocolate one. 
11 - Yes, I remember.

12 - She wanted this one, but this bakery is closed now because of the virus...

13 - I can bake this cake! [pause. Wants to code-switch to English, but tries to remember the word in Russian. Finally, gives in]. How do you say "raspberry" in Russian?

14 - Malina. Yes! Malina sous?

15 - Yes. Raspberry sauce and chocolate. You can check the internet and find the recipe.

16 - I will. I will look for the recipe and do my [instantly code-switches to English] research.

[pronounces the English word without pauses or hesitations, does not make an attempt to say the word in Russian].

17 - Good. I am sure there are a lot of recipes for this cake. But even if this does not work out, you know she just loves everything with chocolate.

18 - True. I can make chocolate mousse!

19 - Oh, I love your chocolate mousse! You cook it to perfection.

20 - I can cook it and put [instantly code-switches to English] on top of the cake.

21- [Na verh torta].

$22-$ Yes!

23 - We also need to check the weather. If the weather is going to be nice, we can grill something. Or if it is going to be cold, we can cook paella or something like that.

24 - Ok. I'll think about it all. But I believe grill-umb would be too good. We should grill-umb. [Here she uses transfer, and combines the English word for grill with Russian verb ending umb].

Analysis: 
As seen from the dialogue, the student uses Russian as the primary language for the conversation with her mother. The topic seems familiar to the student, so she is not hesitant in the word choice except in several cases in lines 13,16, 20, 24. Taking into consideration the classification of code-switching cases presented by Naiditch, L. (2000), I may suggest that the instance of codeswitching to English in line 13 (using the English word for "raspberry") can be explained by irregularity of the use of the word "raspberry" in Russian in this particular family. The same pattern can be traced in lines 16 and 20 (using English "on top of the cake" instead of a Russian expression, and using the English word for "research") because of irregularity of using these words in home settings in Russian. Or, another explanation of code-switching in the mentioned lines as suggested by Heredia \& Altarriba (2001): "bilinguals switch languages whenever a word in a base language is not currently accessible.” (p. 167). Therefore, I can suggest that the codeswitched words were simply not accessible in Russian in the speaker's brain at the time of utterance. As for line 24, the student uses transfer which means that she "uses the target language in a way that is semantically and syntactically appropriate for the other language (but not for the target language), without overtly switching languages” (Marian \& Kaushanskaya, 2006, p. 369).

\section{Dialogue 1 "Family holiday"}

Student 2 - Victor, 18, male

Translated from Russian into English. Bold is used to highlight the instances of code-switching.

1 - Hi dad.

2 - Hi son.

3 - I wanted to talk to you about our family holiday.

4 - Ok. What holiday are we going to talk about?

5 - New Year! It is my favorite. 
6 - Good. Why is it your favorite holiday?

7 - Because I adore how you dress up like Snegurochka [Russian snowmaiden]

8 - Oh yes. And J. dresses up like a Father Frost [Russian Santa Claus]?

9 - Yes! Also, all the family gets together, and we decorate the Yolochka [Christmas tree].

10 - Right. What do we usually decorate it with?

[instantly code-switches to English] - Ornaments. [switches back to Russian] The train, etc.

This is my favorite holiday because in Florida it is not too cold, and not too [forgets the Russian word but tries to remember it, and immediately remembers with his father's hint] hot, right. 11 - Alright. What else... Do you get presents for New Year's?

12 - Yes! And the whole family gets together. I also love watching how Iinstantly code-switches to English] the ball falls.

13 - [Dad instantly switches to English, too]: Oh, that's not Russian.

14 - [Victor and his dad continue arguing in English] Well, they do it in Russia.

$15-N O !$

16 - No, they do!

17 - [Dad switches back to Russian] It's New York where [switches to English again] the ball drops.

18 - [Victor continues in English] Well, we do watch Russian TV.

19 - Yes, we watch the New Year Light [the name of the Russian TV show], but [switches to English again] the ball is New York's thing. It's an American thing.

20 - Okay.

21 - [dad switches back to Russian] And we get together, have a great dinner, exchange presents, invite Ded Moroz and Snegurochka, eat Napoleon cake. 
22 - [conversation continues in Russian] Oh yes! You cook super yummy Napoleon cake! My

favorite. You cook it for two days, right?

23 - Right. It's a long process. What else do we do for New Year?

24 - Oh, we also watch movies. Christmas movies. We watch "S Legkim Parom", the Russian

one, and we also watch [instantly code-switches to English] “Christmas Story”.

Analysis:

This dialogue is a good representation of the assumption that a heritage student would not codeswitch to English very often because he finds himself in the relaxed atmosphere of his home, talking with his close person on a familiar topic. However, a very representative instance of code-switching may be seen in lines 12-17. Victor code-switched to English when he said that the ball dropped for New Year. In line 12, when he mentioned it for the first time, we can suggest that the student did not know the name of this event in Russian because it was the New York event; moreover, when the ball dropped, the TV production was in English. However, later in line 13 we may notice that his dad switched to English as well. In the recording, Victor's dad sounded very emotional because he was sure that Victor was wrong, and the ball never dropped in Russia for New Year. Hearing his dad switching to English, Victor picked up English immediately while also being emotional (lines 14-16). This instance of code-switching might be explained by emotional arousal which was found to be one of the reasons why bilinguals codeswitch (Williams \& Srnivasan, 2019). According to their study, "emotional arousal, especially negative arousal, reduces cognitive control and may trigger spontaneous code-switching” (p. 830). I believe this is what happened in lines 14-16 when Victor became very emotional while trying to convince his father that the ball dropped in Russia, and not in the U.S. Before that instance, Victor had been controlling his speech, and had been trying to speak Russian only, but 
in lines 14-16 his emotions took control over his Russian speech, and that is why he switched to English.

\section{Dialogue 2 “My next semester"}

Student 1 - Natasha, 18, female

Translated from Russian into English. Bold is used to highlight the instances of code-switching. 1 - Natasha, how are you? How are the exams?

2 - Good, everything is good. Exams are a piece of cake!

3 - Wow, really? Are you sure?

4 - Very sure.

5 - Well, good job! What about next semester's schedule? Do you already know what classes you are going to take?

6 - Yes. I will be taking classes from [a hesitant pause, Natasha says the name of her major in Russian but translates it literally from English; the meaning is clear but the word does not sound Russian] Mechanical Engineering.

7 - [Mom is correcting the name of the major in Russian] You would say 'Engineer-mechanic' in Russian.

8 - [Natasha repeating] Engineer-mechanic, yes.

9 - So, which classes are they? Have you already set your mind?

10 - Yes, I will be taking one Math class, MA 262. [switches to English] I don't know how to translate the name of the course in Russian. Differential Equation and Linear Algebra in one class. [switches back to Russian] Secondly, I will be taking a seminar for my ...[switches to English] how to say 'major'? I forgot how to say 'major' in Russian. 
11 - [Mom gives translation]. 'Specialnost'

12 - I will also be taking a [switches to English] sophomore design class.

13 - [Mom tries to translate the name of the course to Russian]. Class on engineering design, I believe.

14 - Yep. And the fourth class will be [switches to English] Dynamics class.

15 - [Mom correcting] 'Dynamika'.

16 - [Natasha repeating] Dynamika. And the fifth class will be Thermodynamika [Here she uses transfer and combines the English word 'thermodynamics' with Russian noun 'termodynamika', so that she pronounces the first part of the word in English, and the second part of the word in Russian]. Finally, I really want to take one more Russian class but I don't know if I will have time.

17 - Well, you have already listed five classes... You can take six classes?

18 - Seminar is only [switches to English] one credit hour.

19 - [Mom correcting in Russian] odin kreditny chas, got it.

20 - [Natasha repeating] odin kreditny chas. And it only lasts half of the semester. That's it. After that I will be finished with this class and will be able to take classes that last the whole semester.

21 - So, you mentioned Dynamics and Thermodynamics. Do you have to take them together? These are difficult classes.

22 - Yes, they need to be taken together. If I don't take them, I won't be able to... Ilong pause. Tries to find Russian equivalent to the word 'prerequisite'. Fails to do so.] 23 - [Mom understands what Natasha is talking about but also fails to find a Russian word for 'prerequisite', so mom code-switches to English, too, but then explains the term with the help 
of the Russian phrase]. Yes, it's a prerequisite. [switches to Russian] So it is a course that you need to take before you will take all the other classes. Can't you take Dynamics in summer instead?

24 - I can. But I believe the class is full. I can check again.

25 - Well, it sounds like a busy semester.

26 - Probably. We'll see.

Analysis:

In this dialogue we can find six instances of Natasha's code-switching to English against four instances of code-switching in Natasha's dialogue 1. The student code-switched only the words related to her academic part of life: "major", "sophomore design class", “dynamics class", "thermodynamics", "one credit hour", and "prerequisite". Here, we might suggest that these words were not currently accessible as in her dialogue 1. Another explanation based on Heredia \& Altarriba (2001) may be applied here: the researchers propose that bilinguals often codeswitch because they do not know either of the languages completely. I agree with this statement when it refers to heritage students because they were growing up in Russian-speaking homes, but were schooled mostly in English, so it often makes one language to be dominant over the other, that is why their language use differs from the situation and environment. Therefore, the instances of code-switched words analyzed above can be explained by the absence of those words in Natasha's Russian vocabulary. Moreover, he stated that she did not know those words.

\section{Dialogue 2 "My next semester"}

Student 2 - Victor, 18, male

Translated from Russian into English. Bold is used to highlight the instances of code-switching. 1 - Hey dad. 
2 - Hi Victor. Have you already registered for the next semester?

3 - Yes, I have registered.

4 - What classes will you be taking?

5 - I will be taking a lot of [switches to English] Aero classes.

6 - [Dad in Russian] How many?

7 - [Victor in Russian] Three [tries to say 'aerospace' classes in Russian, uses transfer]

'aerokosmicheskih' classes. I will have 16 credits next semester.

8 - When does the semester start?

9 - I don't know... Should be in [switches to English] August.

10 - Ok. So, how many classes will you have? Five? Six?

11 - Seven classes.

12 - How many credits, you said?

13 - 16 credits.

14 - Isn't it too many?

15 - No. Oh, actually, 17 credits. I have just [remembers the word] done... registered for the Russian class.

16 - Oh, so you will be taking one more semester of Russian? Great!

17 - Yes, but it will be a [pause] speaking Russian?

18 - Conversational Russian.

19 - Yes, conversational Russian class.

20 - Well, it is very good. You need to continue so that you speak better Russian.

21 - Yeah... my Russian is still bad...

22 - You just need to speak more. 
23 - But you are doing much better: you can read and write a little. You could not do that.

24 - Yes, I did not know how.

25 - So, you are making good progress. Will you be able to take the other Russian class?

$26-$ No ...

27 - Too many classes already?

28 - Yes. Otherwise it will be 4 more credits.

29 - It's too much.

30 - It will be [switches to English] like seventeen plus four... twenty-one! [switches back to Russian] I can't do that.

31 - Can you take it in a semester? In winter?

32 - I don't know yet. I will be taking 13 or 16 credits, we'll see. I don't know how coronavirus will [pause] affect the next semester.

33 - We don't know, right. If the schools are going to open... Do you think it will be necessary to wear a mask, probably?

34 - Yes, I think so.

35 - Will there be a lot of [dad code-switches to English] online classes?

36 - I think it will be online and [pause] I don't know how to say [switches to English] like

fractions. [continues in English] $1 / 4$ of the students will be...

37 - [Dad interrupts in Russian] 'Chast' (part). [continues in Russian] One part of the class

will study online, and the other part on-campus?

38 - Yes. We'll see.

Analysis: 
Overall, we see more instances of code-switching (4) in this dialogue compared to Victor's first dialogue (3). Even though the difference in number of code-switching instances is not that large, one main conclusion can be made: compared to Victor's first dialogue about his family holiday, Victor's second dialogue's code-switching instances all have the same nature of academic vocabulary, just like Natasha's. So, all the words that Victor code-switched to English were related to his studies: “August”, “Aero classes", "fraction”, numbers. The instance of Victor's code-switching when doing basic Math calculations in line 30 is easily explained by the fact that Victor learned Math in English, therefore he was used to counting in English. That is why it was easier and faster for his brain to switch to English, to perform the familiar counting operation in this language. This fact is supported by the bilingual research on Math cognition, which has demonstrated that bilinguals feel more comfortable and perform better in the language in which they have learnt arithmetic in school (Marsh \& Maki, 1976; Martinez, 2019). The same explanation can be used for code-switching of the word "fraction" into English, line 36.

\section{Conclusions}

I agree with Heredia \& Altarriba (2001) who state that "bilingual lexical representation is not a static but a dynamic representational system in which the first language can fall in strength, while the second language becomes the dominant language" (p. 167). Should we conduct the same experiment as described in this paper again, on the same subjects, the answers would likely be different because of the ever-changing and dynamic nature of the language, especially in bilingual heritage speakers.

The conclusions that can be drawn from the current study are as follows: 
1. Every heritage speaker's language and code-switching processes are individual. Even though it is possible to predict instances of code-switching according to the topic of the dialogue, it is impossible to predict all the nuances of code-switched words.

2. The amount of code-switching depends on many factors, however the possible predictors are: the topic of conversation (familiar topic provides fewer opportunities for a bilingual to code-switch), the language of the interlocutor (if the interlocutor code-switches, then a bilingual would rather code-switch as well); the surrounding atmosphere (a bilingual is more likely to code-switch in the unknown place where he/she does not feel comfortable, and vice versa); a bilingual is likely to code-switch for counting in the language of their Math education; a bilingual may code-switch when becoming emotional; a bilingual may code-switch if the necessary word is not activated in mind at the time of conversation; a bilingual will most likely code-switch if the necessary word is simply unknown in the language of conversation.

3. Dubinina \& Polinsky (2013) inform that heritage speakers speak their heritage language to: parents $(85 \%)$, grandparents $(95 \%)$, other adults $(72 \%)$, peers $(12 \%)$. Therefore, going back to the experiment, students had fewer code-switching instances in the dialogue on the social topic because they mostly spoke on this topic with their parents/grandparents at home. Consequently, students had more code-switching instances in the dialogue on the academically complex topic because they mostly spoke on this topic in English with their peers and teachers who were unlikely to know Russian.

\section{Future Research}

This pilot study was the first step of my research. The next steps will include contacting the participants and presenting the proposed explanations of their code-switching instances to them to find out if these explanations match their own ideas of why they code-switched. At the same 
time, it is necessary to collect detailed sociolinguistic background of the students and their families, to trace each of their families' history of immigration and speaking patterns between all the family members in order to research the acquisition of both languages in heritage speakers. Families are big engineers for children's language development. Family language policies, such as restriction or flexibility of language use, can have a great impact on heritage language acquisition. Therefore, it is necessary to find out what were and are the family language policies of the participants. This will include interviewing the participants' parents on the attitude and interference to their children's language use during their upbringing. Finally, it might be useful to trace common instances of speaking heritage language outside the families (e.g. with grandparents back to Russia, with any Russian-speaking friends in the U.S., etc.), and conclude how all the above might have influenced the acquisition of the heritage language, and therefore, the reasons for code-switching.

\section{ABOUT THE AUTHOR}

Deliya Kuleshova is a Ph.D. student at College of Education at Purdue University, the program of study is Literacy and Language Education. Deliya was born and raised in Russia. She graduated from Moscow State Pedagogical University majoring in Teaching English and French. Deliya worked as an English Instructor for four years back in Russia. Then she came to the U.S. to obtain an M.A. degree in TESOL / Linguistics at West Virginia University. There she got acquainted with teaching her native language (Russian) to U.S. students. After graduating from West Virginia University, she started pursuing a Ph.D. degree at Purdue University while continuing to teach Russian as a TA at School of Languages and Cultures.

Inquiries can be made to Deliya Kuleshova: dkuleshov@purdue.edu 
ITJ, 2020 Volume 17, Number 1 


\section{References}

Carreira, M. \& Kagan, O. (2011). The results of the National Heritage Language Survey: Implications for teaching, curriculum design, and professional development. Foreign Language Annals, 44 (1), 40-64. https://doi.org/10.1111/j.1944-9720.2010.01118.x

Dubinina, I. \& Polinsky, M. (2013). Русскоговорящие американцы: лингвистические портреты. American Russian: Linguistic profiles. In: Language in a global context. Язык в глобальном контексте (pp. 95-123). INION.

Isurin, L. (2011). Russian diaspora: Culture, identity, and language change. De Greyter Mouton.

Heredia, R. R., \& Altarriba, J. (2001). Bilingual language mixing: Why do bilinguals codeswitch? Current Directions in Psychological Science, 10(5), 164-168. https://doi.org/10.1111/1467-8721.00140

Kopeliyovich, S. (2010). The variety of Russian as a Heritage language in Israel: Hebrewinduced changes at the abstract level. Instrumentarium of linguistics: Sociolinguistic approaches to non-standard russian. Helsinki.

Library of Congress. (2020, May 8) Immigration. Russian/Polish. Library of Congress. https://www.loc.gov/teachers/classroommaterials/presentationsandactivities/presentations /immigration/polish3.html

Marian, V., \& Kaushanskaya, M. (2007). Cross-linguistic transfer and borrowing in bilinguals. Applied Psycholinguistics, 28, 369-390. https:doi.org/10.1017.S014271640707018X 
Martinez, A. (2019). Language and math: What if we have two separate naming systems? Languages, 4(68). https://doi:10.3390/languages 4030068

Marsh, L.G., \& Maki, R.H. (1976). Efficiency of arithmetic operations in bilinguals as a function of language. Memory \& Cognition, 4, 459-64. https://doi: 10.3758/BF03213203

Myers-Scotton, C. (1993). Dueling languages: Grammatical structure in codeswitching Oxford: Clarendon Press.

Naiditch, L. (2000). Code-switching and -mixing in Russian-Hebrew bilinguals. Studies in Slavic and General Linguistics, 28, 277-282. https://www.jstor.org/stable/40997171

Polinsky, Maria [Serious Science]. (2014, January 30). Heritage language [Video]. YouTube. https://www.youtube.com/watch?v=PKtSAirA_T8

Poplack, S. (2004). Code-switching. In U. Ammon, N. Dittmar, K. J. Mattheier and P. Trudgill (Eds.), Sociolinguistics. An international handbook of the science of language and society, 589-596. Berlin: Walter de Gruyter.

Remennick, L. (2009). Russian immigrants in Israel. In Jewish women: A comprehensive historical encyclopedia. Jewish Women's Archive. https://jwa.org/encyclopedia/article/russian-immigrants-in-israel

Roth, M. (2005). Russian-English code-switching in New York City. Language in Society, 34(3), 485-488. https://www-cambridge-org.ezproxy.lib.purdue.edu/core/services/aopcambridge- 
core/content/view/C0FF92A1580DACC91C85939FFC6B5B6A/S0047404505000163a.p df/russianenglish_codeswitching_in_new_york_city.pdf

Sichyova, O.N. (2005). A note on Russian-English code-switching. World Englishes, 24(4), 487-494. https://onlinelibrary-wileycom.ezproxy.lib.purdue.edu/doi/epdf/10.1111/j.0883-2919.2005.00432.x

Stavans, A. \& Porat, R. (2019). Code-switching in multilingual communities. In S. Montanari \& S. Quay. Eds., Multidisciplinary perspectives on multilingualism (pp. 123-148). De Gruyter.

Williams, A., Srivasan, M., Liu, C., Lee, P., \& Zhou, Q. (2019). Why do bilinguals code-switch when emotional? Insights from immigrant parent-child interactions. Emotion. Advance online publication. http://dx.doi.org/10.1037/emo0000568 